\title{
Study on Sewage Sludge Drying System With Built-in Solar Drying Bed
}

\author{
Zhipan $\mathrm{Gu}^{1}$, Jichun $\mathrm{Yang}^{2}$, Jing Liu ${ }^{2}$, Leren Tao ${ }^{1,3,}{ }^{,}$, Ye Zhang $^{2}$, and Lihao Huang ${ }^{1,3}$ \\ ${ }^{1}$ Instiute of Refrigeration and Cryogenics, School of Energy and Power; University of Shanghai for Science and Technology; Shanghai \\ 200093; PR China \\ ${ }^{2}$ School of Architecture and Civil Engineering; Jiaxing University; Jiaxing; Zhejiang 314001, PR China \\ ${ }^{3}$ Shanghai Key Laboratory of Multiphase Flow and Heat Transfer in Power \\ Engineering, University of Shanghai for Science and Technology, Shanghai 200093, PR China
}

\begin{abstract}
In this paper, the renewable energy solar energy is used as the heat source. The combination of solar drying bed and traditional hot air drying can effectively reduce energy consumption and operation cost. The drying chamber is divided into three layers. The top air supply outlet supplies hot air, the middle layer places wet sludge, and the bottom layer uses hot water coil to dry the sludge. The whole drying process is a heat and mass transfer process with convective heat transfer and radiation heat transfer. After analysis and comparison with traditional energy drying, it is found that drying $97.5 \mathrm{~kg}$ of sewage sludge will save $79 \%$ energy, save $12.84 \mathrm{~kg}$ of standard coal, reduce $32 \mathrm{~kg}$ of carbon dioxide and $1.284 \mathrm{~kg}$ of sulphur dioxide.
\end{abstract}

\section{Introduction}

Sewage sludge is produced as a by-product in the process of sewage treatment. It contains a lot of water and refractory organics, heavy metals and salts, pathogenic bacteria, parasite eggs, etc[1]. Sewage sludge is a complex mixture of water, inorganic compounds, microorganism and certain undigested substances [2]. It may cause secondary pollution, and even harmful components may eventually enter the food chain[3]. With the development of global economy, sewage sludge is produced in large quantity worldwide. In 2013, China's total dry sludge output was 6.25 million tons. Canada and the United States produce approximately 660,000 tons and 6.5 million tons of dry sludge annually[4]. Due to the large volumes of sludge, the focus has shifted towards reduction, stabilization, harmlessness, and resource utilization of sludge. The thermal drying is an essential intermediate stage for sludge management. Traditional thermal drying needs more fossil energy. Access to renewable, clean and cheap energy is a major issue in socio-economic development. In recent years, sustainable and renewable energy resource like solar energy is widely applied in drying process.

There are many examples in the literature on using solar energy in agriculture, food production as an energy source. Khanlari et al. [5] experimentally and numerically analyzed the effect of simple tube-type solar air heater in drying applications. Hatami et al. [6] experimentally and numerically analyzed an indirect solar dryer to be used in drying agricultural products. Elmustapha et al. [7] conducted a cross case analysis of solar thermal and solar photovoltaic systems. Kasaeian et al. [8] analyzed the solar radiation, storing heat, extracting, and the application of solar ponds in the recent decades. Tong et al. [9] investigated different nanofluids to enhance thermal performance of a flat-plate solar collector. VeraMedina et al. [10] experimentally and numerically developed a new freeze protection system by using flexible silicone peroxide tubes inside the absorber of the solar collector. Poblete et al.[11] pointed out that drying air flow rate is the most important factor that affect the performance of a closed solar dryer. Karthikeyan et al.[12] indicated that drying air temperature has significant effect on dried agricultural product quality through research on a solar tunnel dryer.

This work adopts the combination of solar drying bed and traditional solar drying technology. Solar collector and solar drying bed are used to convert solar energy into heat energy, and the sewage sludge is heated and dried, so that the moisture in the sludge can be transported and vaporized to achieve the effect of sludge reducing moisture content. This provides a new research idea for the exploration and development of an efficient, environmental friendly and energy saving sludge resource treatment system. Sewage

\section{Sewage sludge drying System}

\subsection{Formatting the title, authors and affiliations}

* Corresponding author: cryo307@usst.edu.cn (Leren Tao ) 
The schematic diagram of sludge drying system of solar drying bed is shown in Fig. 5. The system components are shown in Table 1.

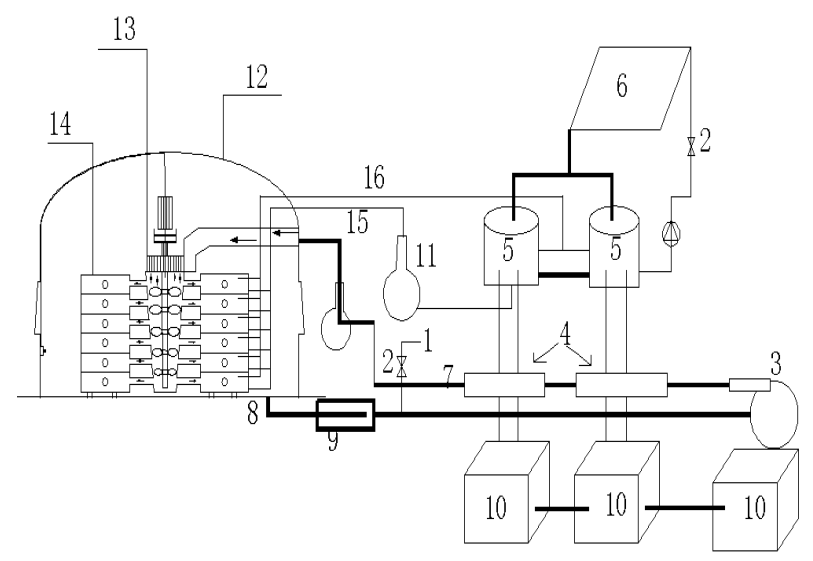

Fig. 1. Sludge drying system of solar drying bed

Table 1. System components.

\begin{tabular}{|c|c|c|c|}
\hline Serial number & Expression & Serial number & Expression \\
\hline 1 & Air & 9 & Dehumidifier \\
\hline 2 & Valve & 10 & $\begin{array}{c}\text { Underground } \\
\text { Hot Water } \\
\text { Tank } \\
\end{array}$ \\
\hline 3 & Blower & 11 & Pump \\
\hline 4 & $\begin{array}{c}\text { Heat } \\
\text { Exchanger }\end{array}$ & 12 & Drying Room \\
\hline 5 & $\begin{array}{c}\text { Heat } \\
\text { Preservation } \\
\text { Water Tank }\end{array}$ & 13 & Air Distributor \\
\hline 6 & $\begin{array}{c}\text { Solar } \\
\text { Collector }\end{array}$ & 14 & $\begin{array}{l}\text { Drying } \\
\text { chamber }\end{array}$ \\
\hline 7 & Air Pipe & 15 & $\begin{array}{c}\text { Water Supply } \\
\text { Pipe }\end{array}$ \\
\hline 8 & $\begin{array}{l}\text { Return Air } \\
\text { pipe }\end{array}$ & 16 & $\begin{array}{c}\text { Water Return } \\
\text { Pipe }\end{array}$ \\
\hline
\end{tabular}

\subsection{System operation}

The whole sludge drying system is composed of two parts: one is solar sludge drying bed, the other is hot air convection drying. The heat of both systems comes from the solar collector, which produces hot water stored in a hot tank. Part of the hot water enters the heat exchanger to heat the air, and the hot air is sent to the drying chamber through the fan. It passes through the heat transfer between the sludge surface and the sludge interior, so that the water in the sludge gradually vaporizes and enters the return air pipe together with the wet air. The other part of hot water in the hot water tank is fed into the inner coil of the drying bed through the water supply pipe, and flows into the hot water tank through the return pipe after heat exchange.

\subsection{Sludge drying chamber}

In this system, the sludge drying chamber is a combination of hot air convection drying and drying bed drying. The sewage sludge drying chamber is shown in Fig. 2. In the drying chamber, the drying box is used to dry the sludge layer by layer, which improves the drying efficiency. The drying chamber is divided into three layers. The top air supply outlet supplies hot air, the middle layer places wet sludge, and the bottom layer uses hot water coil to dry the sludge. The whole drying process is a heat and mass transfer process with convective heat transfer and radiation heat transfer. The whole process of the system is simple, which reduces the loss of heat energy and improves the utilization rate of heat energy. Compared with the traditional thermoelectric drying system, the energy consumption and pollutant emission are greatly reduced.

Vent pipe Hot air outlet

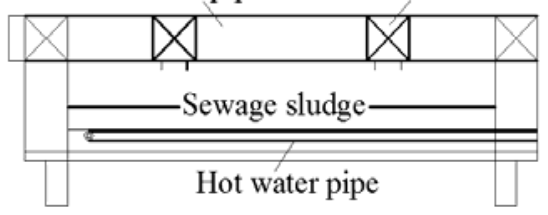

Fig. 2. Sludge drying chamber

\section{Theoretical design calculation}

\subsection{Thermal calculation}

According to the law of conservation of energy, the thermodynamic balance calculation of sludge drying system has the following energy conservation relations.

$$
Q_{\mathrm{ss}}+Q_{\mathrm{w}}+Q_{\mathrm{L}}=Q_{\mathrm{so}}
$$

Where $Q_{\mathrm{ss}}$ is the heat required for drying sludge $(\mathrm{KJ})$, $Q_{\mathrm{w}}$ is heat required for evaporation of water $(\mathrm{KJ}) . Q_{\text {so }}$ is the heat provided by solar drying system. $Q_{\mathrm{L}}$ is the heat loss during drying $(\mathrm{KJ})$.

$$
\begin{gathered}
Q_{\mathrm{ss}}=M_{2}\left(T_{2}-T_{1}\right)\left[\left(1-R_{2}\right) C_{\mathrm{s}}+R_{2} C_{\mathrm{i}}\right] \\
M_{2}=M_{1}\left(1-R_{1}\right) /\left(1-R_{2}\right)
\end{gathered}
$$

Where $M_{2}$ is the sludge mass at a certain moisture content after drying $(\mathrm{kg}) . T_{1}$ and $T_{2}$ are the temperature of sludge before and after drying $\left({ }^{\circ} \mathrm{C}\right) . R_{2}$ is the moisture content of dried sewage sludge $(\%) . C_{\mathrm{s}}$ is the specific heat of the sewage sludge $\left(\mathrm{KJ} /\left(\mathrm{Kg} \cdot{ }^{\circ} \mathrm{C}\right)\right) . C_{\mathrm{s}}$ is the specific heat of the water $\left(\mathrm{KJ} /\left(\mathrm{Kg} \cdot{ }^{\circ} \mathrm{C}\right)\right) . M_{1}$ is the sludge mass at a certain moisture content before drying $(\mathrm{kg}) . R_{1}$ moisture content of sludge before drying (\%).

$$
\begin{gathered}
Q_{\mathrm{w}}=W\left[r_{\mathrm{i}}+\left(T_{2}-T_{1}\right) C_{\mathrm{i}}\right] \\
W=M_{2}\left(1-R_{2}\right) /\left(x_{1}-x_{2}\right) \\
x=R /(1-R)
\end{gathered}
$$


Where $W$ is evaporation water $(\mathrm{kg}) . r_{\mathrm{i}}$ is the latent heat of vaporization of water $(\mathrm{kJ} / \mathrm{kg}) . \quad x_{1}$ and $x_{2}$ are moisture content of dry basis before and after drying.

$$
Q_{\mathrm{L}}=\alpha\left(Q_{\mathrm{ss}}+Q_{\mathrm{w}}\right)
$$

Where $\alpha$ is Heat loss coefficient in drying process.

The thickness of sludge in each layer is $20 \mathrm{~cm}$, and the moisture content of each layer of sludge is $80 \%$. After weighing, the weight of each layer of sludge is $97.5 \mathrm{~kg}$.

It takes 1 hour to dry the first layer of sludge. The $97.5 \mathrm{~kg}$ sludge with $80 \%$ moisture content is treated to make the moisture content of sewage after drying reach $50 \%$, the specific heat capacity of sludge $C_{\mathrm{s}}=1.244$ $\mathrm{KJ} /\left(\mathrm{Kg} \cdot{ }^{\circ} \mathrm{C}\right)$, and the density $\rho=1.3 \times 10 \mathrm{Kg} / \mathrm{m}^{3}$.

$$
\begin{gathered}
M_{2}=97.5 \times(1-80 \%) /(1-50 \%)=39 \mathrm{~kg} \\
W=39 \times(1-50 \%) /(4-1)=58.5 \mathrm{~kg} \\
Q_{\mathrm{w}}=58.5 \times[2257.2+(40-20) \times \\
4.1868]=136968.15 \mathrm{KJ} \\
Q_{\mathrm{ss}}=39 \times(40-20)[(1-50 \%) \times 1.244+0.5 \times \\
4.1868]=2118.02 \mathrm{KJ} \\
Q_{\mathrm{L}}=0.05 \times(136968.15+2118.02)=6954.3 \mathrm{KJ} \\
Q_{\mathrm{so}}=136968.15+2118.02+6954.3=146010.5 \mathrm{KJ}
\end{gathered}
$$

\subsection{Calculation of solar collector area}

The calculation formula of solar collector area is as follows

$$
A_{\mathrm{c}}=\left(Q_{\mathrm{so}}-Q_{0}\right) f / J_{\mathrm{T}} \eta_{\mathrm{cd}}\left(1-\eta_{\mathrm{L}}\right)
$$

Where $A_{\mathrm{c}}$ is the collection area of the solar collector $\left(\mathrm{m}^{2}\right), Q_{0}$ is heat stored in drying chamber $(\mathrm{KJ}) . f$ is the guarantee rate of solar energy is $30 \%-80 \%$, according to the solar radiation during the service life of the system, system economy and user requirements. $J_{\mathrm{T}}$ is the annual average daily solar radiation on the day lighting surface of the local collector $\left(\mathrm{KJ} / \mathrm{m}^{2}\right) . \eta_{\mathrm{cd}}$ is the annual average collection efficiency of the collector, according to the experience, the value is $0.25-0.50$, and the specific value should be determined according to the actual test results of the collector. $\eta_{\mathrm{L}}$ is the heat loss rate of the collector pipeline. According to experience, the value $\left(\eta_{\mathrm{L}}\right)$ is 0.20 0.30 .

When calculating the heat collection area of solar energy drying system, it is considered that the sludge drying room can provide part of the heat needed for sludge drying, so the heat collection area of solar collector can be reduced. In summer, the temperature in the solar greenhouse can reach about $60{ }^{\circ} \mathrm{C}$, and the air quantity needed for drying per hour is $6541.25 \mathrm{~m} 3 / \mathrm{h}$ after measurement. The heat provided by hot air is $180997.56 \mathrm{~kJ}$. The heat stored in drying chamber $\left(Q_{0}\right)$ is set to $40 \%$ of the heat provided by the hot air.

$$
\begin{gathered}
A_{\mathrm{c}}=(146010.5-180997.56 \times 40 \%) \times 0.475 /(2268 \times \\
0.5(1-0.3) \approx 45 \mathrm{~m}^{2}
\end{gathered}
$$

The sludge drying system is installed in Jiaxing City, Zhejiang Province. The solar collector is located in the same direction as the building, facing due south, and the inclination angle is the same as the local latitude. 50 pieces of horizontal plug-in vacuum tube collector with the specification of $47 \times 1500 \mathrm{~mm}$ are selected as a unit collector. The unit collector size is $3100 \mathrm{~mm} \times 1647 \mathrm{~mm}$ in width. The heat collection area of unit collector is $5.11 \mathrm{~m}^{2}$. According to the total area of the collector and the heat collection area of the unit collector, the number of collectors required is calculated to be 9 groups.

\section{Energy saving analysis}

Solar sludge drying equipment can convert solar energy into heat energy through solar energy conversion equipment, effectively reducing the use of traditional energy.

According to the amount of $97.5 \mathrm{~kg}$ sludge per hour, the energy consumption of traditional electric heating per hour is $40.6 \mathrm{KWh}$. The energy consumption of electrical equipment such as pumps and fans in the solar sludge drying system is estimated to be $8.5 \mathrm{kw} / \mathrm{h}$. Compared with the traditional electric heating, the energy consumption is reduced by $79 \%$. The use of solar energy sludge drying equipment can effectively reduce energy consumption. At the same time, the command and control system of water pump and fan can further reduce the power consumption of system electrical equipment, and the energy saving effect is remarkable.

\section{Emission reduction analysis}

According to the research, saving $1 \mathrm{kwh}$ electricity can save $0.4 \mathrm{~kg}$ standard coal and reduce pollution emission of $0.997 \mathrm{~kg}$ carbon dioxide and $0.03 \mathrm{~kg}$ sulfur dioxide. According to the previous calculation results, drying $97.5 \mathrm{~kg}$ sludge per hour can save $32.1 \mathrm{kwh}$ of electric energy. It can save $12.84 \mathrm{~kg}$ of standard coal, reduce 32 $\mathrm{kg}$ of carbon dioxide and $1.284 \mathrm{~kg}$ of sulfur dioxide.

The energy saving and emission reduction calculated above is only one layer of sludge energy saving and emission reduction in drying chamber. The whole drying chamber can be composed of four to five layers, which can save more energy and reduce more greenhouse gas emissions.

\section{Application prospect analysis}

The research technology of this system can effectively solve the drying problem of sludge in urban sewage treatment plant, and reduce the energy consumption in the process of harmless, reducing and resource treatment of urban sludge.

This system is expected to be promoted and used in BOT mode or as the technical transformation project of sewage treatment plant, which is suitable for sludge 
treatment project of sewage treatment plant in small and medium-sized cities. The technical field is in development. Due to the small amount of single project, most domestic large and medium-sized enterprises have not set foot in it. At present, it is the best entry period for solar energy to apply dry sludge market. This system can take advantage of the technical advantages of independent research and development, and will become a market leader after industrialization.

\section{Conclusion}

In this system, the solar collector is used to convert solar energy into heat energy to heat and dry the sludge, so as to transfer and evaporate the water in the sludge, so as to reduce the water content of the sludge. Compared with traditional electric heating, drying $97.5 \mathrm{~kg}$ of sewage sludge will save $79 \%$ energy, save $12.84 \mathrm{~kg}$ of standard coal, and reduce $32 \mathrm{~kg}$ of carbon dioxide and $1.284 \mathrm{~kg}$ of sulphur dioxide. This provides a new research idea for the exploration and development of efficient, environmental protection, energy-saving sludge treatment system.

The system uses renewable energy solar energy as heat source, and its operation and management are simple. It can effectively reduce the energy consumption and operation cost of drying. It has a good application prospect.

\section{Acknowledgments}

This work was supported by Zhejiang Provincial Natural Science Foundation of China [No. LQ19E080014], Public Welfare Technology Research Plan of Zhejiang Province [No. LGG19E060005], Science and Technology Program of Ministry of Housing and UrbanRural Development China [2015-K7-026] and Project of Key Laboratory of Shanghai [1N-15-301-101].

\section{References}

1. G.Yang, G. Zhang, H.Wang, Water Res, 2015, 78, 60-73.

2. E. Eriksson, N. Christensen, J.E. Schmidt, A. Ledin, Desalination, 2008, 226, 371-388.

3. A. Pathak, M.G. Dastidar, T.R. Sreekrishnan, J. Environ. Manage,2009, 90, 2343-2353.

4. A.K. Wahidunnabi, C. Eskicioglu, Water. Res, 2014, 66, 430-446.

5. A. Khanlari, H.O. Güler, A.D. Tuncer, C. Sirin, Y.C. Bilge, Y. Yılmaz, A. Güngor, Renew. Energy, 2020, 145, 1677-1692.

6. S.Hatami, G.Payganeh, A.Mehrpanahi, J. Clean. Prod. 2020, 244, 118809.

7. H. Elmustapha, T. Hoppe, H. Bressers, J. Clean. Prod. 2018, 186, 155-167.

8. A. Kasaeian, S. Sharifi, W.M. Yan, Sol. Energy, 2018, 174, 189-206.
9. Y. Tong, H. Lee, W. Kang, H. Cho, Appl. Therm. Eng. 2019, 159, 113959.

10. J. Vera-Medina, I. Lillo-Bravo, J.Hernandez, M. Larraneta, Appl. Therm. Eng, 2018, 135, 446-453.

11. R. Poblete, E. Cortes, J. Macchiavello, J. Bakit, Renew. Energy, 2018, 126, 978-986.

12. A.K. Karthikeyan, S. Murugavelh, Renew. Energy, 2018, 128, 305-312. 